\title{
EVALUASI ASPEK TRANSPORTASI TEMPAT PERISTIRAHATAN DI KM 88A TOL PURBALEUNYI
}

\author{
Ni Luh Putu Shinta Eka Setyarini ${ }^{1}$, MI Dewi Linggasari ${ }^{2}$ \\ ${ }^{1}$ Program Studi Sarjana Teknik Sipil, Universitas Tarumanagara, Jl. Letjen S. Parman No.1 Jakarta \\ Email: niluhs@ft.untar.ac.id \\ ${ }^{2}$ Program Studi Sarjana Teknik Sipil, Universitas Tarumanagara, Jl. Letjen S. Parman No.1 Jakarta \\ Email: dewil@ft.untar.ac.id
}

\begin{abstract}
ABSTRAK
Meningkatnya kepadatan penduduk dan jumlah pendapatan telah memberikan dampak pada meningkatnya mobilitas akibat variasi kegiatan dan tata guna lahan yang dapat dilihat dari pergerakan transportasi antar kota yang terus bertambah. Jalan Tol Purbaleunyi merupakan jalan alternatif untuk mengurangi kepadatan lalulintas di jalan arteri dari Daerah Khusus Ibukota Jakarta dan sekitarnya ke kota Bandung atau sebaliknya. Sehingga tol ini selalu ramai dilalui oleh kendaraan, akibatnya sering terjadi kepadatan bahkan macet. Padatnya lalu lintas serta panjangnya ruas jalan tol ini dapat menyebabkan pengemudi jenuh, lelah hilang konsentrasi dan bahkan mengantuk. Kondisi ini dapat membahayakan dirinya sendiri serta pengemudi lain, oleh karena itu perlu dibangun tempat peristirahatan sebagai fasilitas penunjang keselamatan di jalan tol. Hadirnya tempat peristirahatan km 88 A Tol Purbaleunyi dapat membantu pengemudi yang lelah agar beristirahat terlebih dahulu sebelum melanjutkan perjalanannya kembali. Pelayanan serta fasilitas di dalam tempat peristirahatan tidak kalah penting agar pengemudi dan penumpang dapat memenuhi segala kebutuhannya seperti makan, minum dan beristirahat melepas lelah yang harus sesuai dengan Standar Pelayanan Minimal (SPM) peratitan menteri PUPR No. 16/PRT/M/2014. Metode yang akan dipergunakan adalah pengukuran kualitas layanan dengan importance performance analysis (IPA), dan juga SPM. Pengambilan data dengan cara observasi langsung dan kuesioner yang akan dibagikan kepada 100 responden dimana 50 sampel wawancara dan 50 sampel dengan online. Dari data 100 responden akan diperoleh data mean persepsi dan mean harapan dari diagram kartesius IPA. Dari hasil skor IPA, akan dibandingkan dengan kenyataan saat survei langsung dilapangan apakah sesuai atau ada perbedaan pada hasil penelitian tersebut.

Kata kunci: Tempat Peristirahatan, fasilitas, pelayanan, memenuhi kebutuhan.
\end{abstract}

\section{PENDAHULUAN}

Jumlah populasi penduduk yang terus meningkat dari waktu ke waktu telah memberikan kontribusi terhadap meningkatnya mobilitas orang, barang dan jasa, yang dapat dilihat dari pergerakan transportasi antar kota yang terus bertambah. Jalan tol Purbaleunyi merupakan ruas jalan yang dibuat untuk mengurangi kepadatan jalan arteri antar Provinsi yang menghubungkan Daerah Khusus Ibukota Jakarta dengan kota metropolitan Bandung dan sekitarnya. Berdasarkan Peraturan Pemerintah Nomor 15 Tahun 2005 tentang jalan tol, pasal 7 ayat 2, "Pada jalan tol antarkota harus tersedia tempat istirahat dan pelayanan untuk kepentingan pengguna jalan tol" dan ayat 3, "Tempat istirahat dan pelayanan sebagaimana dimaksud pada ayat (2), disediakan paling sedikit satu tempat peristirahatan untuk setiap jarak 50 (lima puluh) kilometer pada setiap jurusan. Panjang nya jarak tempuh jalan tol Purbaleunyi ini mengharuskan adanya paling sedikit 2 rest area sebagai sarana peristirahatan.

Rest area merupakan kebutuhan bagi para mengguna jalan tol, oleh karena itu harus memiliki fasilitas yang lengkap dan nyaman, maka pihak pengelola harus memenuhi Standar Pelayanan Minimal (SPM) berdasarkan Peraturan Menteri Pekerjaan Umum No. 16/PRT/M/2014 untuk fasilitas dan dalam mengelola rest area. Disamping fasilitas rest area, aspek transportasi seperti akses keluar - masuk yang mudah, kapasitas parkir mencukupi jumlah pengunjung yang datang, dan kondisi perkerasan jalan yang layak.

Menurut Atri, Yuanita Setyo.2010 ; Atmi, Fety Widi. 2014 dan Adelia Destiasri. 2011, harapan dan keinginan dari setiap pengguna jalan tol akan ketersediaan fasilitas dan jumlah pelayanan yang memadai di tempat peristirahatan haruslah dipenuhi. Pengelola harus mengelola serta 
menyediakan fasilitas - fasilitas pada tempat peristirahatan sesusai dengan Standar Pelayanan Minimal (SPM). Fasilitas-fasilitas yang wajib memiliki kualitas yang baik seperti:

A. Tempat Istirahat yang memiliki fasilitas toilet, tempat duduk, tempat ibadah, stasiun pengisian bahan bakar, tempat makan, pusat informasi, bengkel, atm, dll.

B. Kapasitas parkir yang mencukupi untuk pengguna tempat istirahat.

C. Jalan akses tempat peristirahatan yang efisien, tidak ada hambatan, dan tidak berlubang.

D. Tempat peristirahatan sebagai tempat untuk rekreasi sehingga harus memiliki keindahan landscape dan arsetektural

Tujuan dari penelitian ini adalah untuk mengevaluasi pelayanan fasilitas di tempat istirahat berdasarkan Standar Pelayanan Minimal, Mengetahui persepsi pengelola terhadap tempat peristirahatan yang dikelolanya, mengetahui indeks parkir pada tempat peristirahatan, mengetahui alur kendaraan di lingkungan tempat peristirahatan.

Pemahaman tempat peristirahatan

Tempat peristirahatan atau tempat peristirahatan adalah suatu tempat dan fasilitas yang disediakan bagi pemakai jalan sehingga baik pengemudi, penumpang maupun kendaraannya dapat beristirahat untuk sementara karena alasan lelah dalam perjalanan jarak jauh. Tempat peristirahatan memiliki fungsi utama sebagai fasilitas pengembalian kebugaran atau kesiapan sehingga aktivitas dapat dilanjutkan kembali. Dalam pembangunan tempat peristirahatan, Pengelola harus mengelola serta menyediakan fasilitas - fasilitas pada tempat peristirahatan sesuai dengan Standar Pelayanan Minimal (SPM), Standar Pelayanan Minimum dapat dilihat pada Tabel 1:

Tabel 1. Standar Pelayanan Minimal (SPM)

\begin{tabular}{|c|c|c|c|c|}
\hline \multirow{8}{*}{$\begin{array}{l}\text { Tempat } \\
\text { Peristirahatan } \\
\text { (TI), dan Tempat } \\
\text { Istirahat dan } \\
\text { Pelayanan (TIP) }\end{array}$} & Kondisi Jalan & $\begin{array}{l}\text { Seluruh } \\
\text { Permukaan Jalan } \\
\text { di } \quad \text { Tempat } \\
\text { Persitirahatan }\end{array}$ & $\begin{array}{lr}\text { Tidak } & \text { Ada } \\
\text { Lubang, } & \text { Retak, } \\
\text { dan Pecah } & \end{array}$ & $\begin{array}{l}\text { Waktu } \\
\text { Pemenuhan } 2 \text { x } 24 \text { Jam }\end{array}$ \\
\hline & On/Off Ramp & $\begin{array}{ll}\text { Permukaan Jalan } \\
\text { di Jalur } & \text { Masuk } \\
\text { dan } & \text { Keluar } \\
\text { Tempat Istirahat }\end{array}$ & $\begin{array}{lr}\text { Tidak } & \text { Ada } \\
\text { Lubang, } & \text { Retak } \\
\text { dan Pecah } & \end{array}$ & $\begin{array}{l}\text { Waktu } \\
\text { Pemenuhan } 2 \times 24 \text { Jam }\end{array}$ \\
\hline & Toilet & $\begin{array}{l}\text { Fungsi } \\
\text { Manfaat }\end{array}$ & $\begin{array}{l}\text { Berfungsi } 100 \% \text {, } \\
\text { Bersih, Gratis }\end{array}$ & $\begin{array}{l}\text { Waktu } \\
\text { Pemenuhan } 2 \text { x } 24 \text { Jam }\end{array}$ \\
\hline & $\begin{array}{l}\text { Parkir } \\
\text { Kendaraan }\end{array}$ & $\begin{array}{l}\text { Fungsi } \\
\text { Manfaat }\end{array}$ & $\begin{array}{l}\text { Berfungsi } 100 \% \text {, } \\
\text { Teratur, Bersih, } \\
\text { Gratis } \\
\text { Dilarang Parkir } \\
\text { di On/Off Ramp }\end{array}$ & $\begin{array}{l}\text { Jalan dan Perpakiran hanya } \\
\text { Diperuntukan bagi } \\
\text { Pengguna Jalan Tol }\end{array}$ \\
\hline & Penerangan & $\begin{array}{l}\text { Fungsi } \\
\text { Manfaat }\end{array}$ & Berfungsi 100\% & $\begin{array}{l}\text { Mengacu kepada Standar } \\
\text { PJU }\end{array}$ \\
\hline & $\begin{array}{l}\text { Stasiun } \\
\text { Pengisian Bahan } \\
\text { Bakar }\end{array}$ & $\begin{array}{l}\text { Fungsi } \\
\text { Manfaat }\end{array}$ & Berfungsi 100\% & $\begin{array}{ll}\text { Mengacu } & \text { kepada } \\
\text { Ketetapan ESDM } & \end{array}$ \\
\hline & Bengkel Umum & $\begin{array}{l}\text { Fungsi } \\
\text { Manfaat }\end{array}$ & Berfungsi $100 \%$ & $\begin{array}{l}\text { Bengkel harus Memiliki } \\
\text { Ijin Usaha }\end{array}$ \\
\hline & $\begin{array}{l}\text { Tempat Makan } \\
\text { dan Minum }\end{array}$ & $\begin{array}{l}\text { Fungsi } \\
\text { Manfaat }\end{array}$ & Berfungsi 100\% & $\begin{array}{l}\text { Wajib Memberikan } \\
\text { Informasi Harga Makanan } \\
\text { dan Minuman yang Dijual }\end{array}$ \\
\hline
\end{tabular}

Kapasitas dan durasi parkir 
Survei lapangan berdasarkan aspek transportasi meliputi kapasitas ruang parkir, durasi parkir dan indeks parkir. Rumus durasi parkir dan metode survey. Menurut Leksmono S. Putranto, hal - hal yang harus diperhatikan yakni:

- $\quad$ Kapasitas ruang parkir. Kapasitas ruang parkir merupakan kemampuan maksimum ruang tersebut dalam menampung kendaraan, dalam hal ini adalah volume kendaraan pemakai fasilitas parkir tersebut. Data didapat dengan menghitung langsung jumlah slot yang ada di lapangan.

- Durasi parkir. Durasi adalah rata-rata lama waktu yang dipakai setiap kendaraan untuk berhenti pada ruang parkir. Berdasarkan hasil perhitungan durasi dapat diketahui rata-rata lama penggunaan ruang parkir oleh pemarkir. Durasi ini mengindikasikan apakah diperlukan suatu pembatasan waktu parkir (dilihat dari rata-rata durasi parkirnya). (Oppenlender, 1976)

- Indeks Parkir. Indeks parkir (IP) adalah perbandingan antara akumulasi parkir dengan kapasitas ruang parkir yang tersedia. Nilai indeks parkir ini dapat menunjukkan seberapa besar kapasitas parkir yang telah terisi. Besarnya indeks parkir yang tertinggi diperoleh dari perbandingan antara akumulasi parkir dengan kapasitas parkir. Besaran indeks parkir ini akan menunjukkan apakah kawasan parkir tersebut bermasalah atau tidak.

\section{Importance Performance Analysis (IPA)}

Untuk menjawab masalah sejauh mana keandalan infrastruktur tempat peristirahatan, maka digunakan Importance Performance Analysis / Analisis Kuadran. Analisis tersebut adalah sebuah teknik analisis deskriptif yang diperkenalkan oleh John A. Martilla dan John C. James tahun 1977. IPA adalah suatu teknik analisis yang digunakan untuk mengidentifikasi faktor-faktor kinerja penting apa saja yang harus ditujukan. Fungsi utama IPA juga untuk menampilkan informasi yang berkaitan dengan faktor pelayanan yang menurut para pengguna jasa sangat mempengaruhi kepuasan dan ketertarikan mereka dan faktor lain yang harus di tingkatkan karena mungkin belum memuaskan. Metode ini juga memudahkan penjelasan data dan mendapatkan masukan praktis karena menggabungkan pengukuran faktor tingkat kepentingan dengan tingkat kepuasan dalam sebuah grafik dua dimensi dan mudah diinterpretasi. Ciri khas dari teknik analisis metode IPA adalah penggunaan kuadran kartesian.

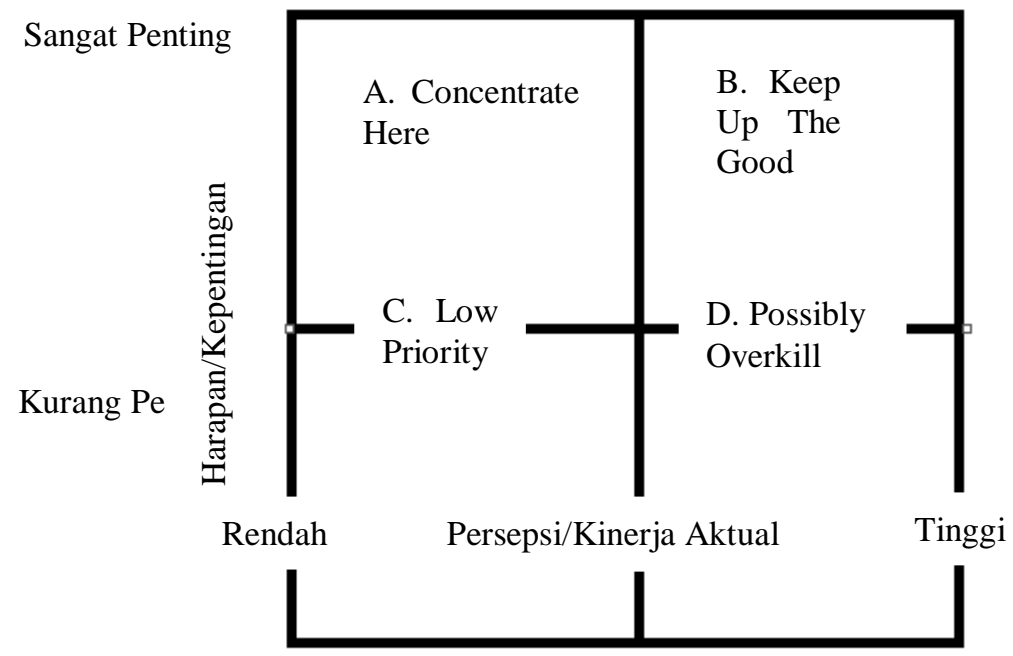

Gambar 1. Kuadran Importance Performance Analysis

Sumber: Brandt, 2000

Dalam menginterpretasi kuadran, keduanya merinci sebagai berikut: 
a. Concentrate Here (konsentrasi di sini). Faktor-faktor yang terletak dalam kuadran ini dianggap sebagai faktor yang penting dan atau diharapkan oleh konsumen tetapi kinerja aktual yang ada pada saat ini belum memuaskan sehingga pengelola berkewajiban mengalokasikan sumber daya untuk meningkatkan kinerja factor-faktor tersebut. Faktorfaktor yang terletak pada kuadran ini merupakan prioritas untuk ditingkatkan.

b. Keep up with the good work (pertahankan prestasi). Faktor-faktor yang terletak pada kuadran ini dianggap Penting dan diharapkan sebagai faktor penunjang bagi kepuasan konsumen sehingga pengelola berkewajiban memastikan bahwa kinerja institusi yang dikelolanya dapat terus mempertahankan prestasi yang telah dicapai.

c. Low Priority (prioritas rendah). Faktor-faktor yang terletak pada kuadran ini mempunyai tingkat persepsi atau kinerja aktual yang rendah atau dianggap tidak terlalu Penting dan atau terlalu diharapkan oleh konsumen sehingga manajemen tidak perlu memprioritaskan pada faktor-faktor tersebut.

d. Possibly Overkill (terlalu berlebih). Faktor-faktor yang terletak pada kuadran ini dianggap tidak terlalu penting dan atau tidak terlalu diharapkan sehingga pihak manajemen perlu mengalokasikan sumber daya dari faktor-faktor tersebut kepada faktor-faktor lain yang mempunyai prioritas penanganan lebih tinggi semisal di kuadran B.

Batasan Penelitian

Dalam penulisan skripsi ini permasalahan dibatasi hanya pada pengaruh kualitas pelayanan suatu fasilitas yang meliputi kecukupan dan kelayakan pada tempat peristirahatan dari aspek transportasi dengan kepuasan pengguna jalan tol Purbaleunyi. Dalam hal ini penulis membatasi wilayah penelitian atau pengumpulan data adalah pada tempat peristirahatan tol Purbaleunyi KM 88A. Pengumpulan data dilakukan dengan metode observasi, kuesioner, angket dan analisis statistik.

Rumusan Masalah

Berdasarkan identifikasi permasalahan yang diuraikan sebelumnya dapat dirumuskan masalah yang diangkat dalam penelitian ini adalah:

1. Bagaimanakah standar fasilitas di tempat peristirahatan terhadap SPM (Standar Pelayanan Minimal)?

2. Apakah kapasitas parkir memenuhi jumlah pengunjung?

3. Apakah fasilitas dan kualitas tempat peristirahatan sudah sesuai dengan harapan pengguna?

Tujuan Penelitian

Penelitian ini bertujuan untuk menganalisis :

1. Evaluasi pelayanan fasilitas di tempat istirahat berdasarkan SPM.

2. Mengetahui persepsi pengunjung terhadap tempat peristirahatan KM88A.

3. Untuk mengetahui indeks parkir pada tempat peristirahatan.

4. Untuk mengetahui alur kendaraan di lingkungan tempat peristirahatan.

\section{METODOLOGI PENELITIAN}

\section{A. Tahapan penelitian}

Penelitian dilakukan dengan pengambilan menggunakan metode observasi langsung di lapangan dan pembagian kuesioner melalui wawancara langsung dan on line. Data yang 
didapat berupa data primer dan data sekunder. Data primer terdiri dari data hasil pembagian kuesioner, dan data hasil observasi berupa data kapasitas parkir, dan durasi parkir. Sedangkan data sekunder terdiri dari Site Layout dan struktur organisasi tempat peristirahatan. Data hasil kuesioner diolah dengan metode IPA, namun sebelum diolah dilakukan uji validitas dan realibilitas terlebih dahulu, sedangkan untuk data hasil observasi diolah dengan formulasi durasi parkir dan metode survei lapangan.

B. Metode analisis data

Untuk menjawab permasalahan sampai sejauh mana keandalan infrastruktur tempat peristirahatan, maka digunakan IPA. Ciri khas dari teknik analisis metode IPA adalah penggunaan kuadran kartesian. Persoalannya adalah bagaimana membuat titik pusat untuk garis $\mathrm{x}$ dan garis $\mathrm{y}$ (Brandt, Latu, dan Everett. (2000)

Uji beda harapan dan persepsi dilakukan guna menguji apakah terdapat kesenjangan (gap) antara harapan dengan persepsi dalam variabel yang dianalisis. Uji dilakukan dengan membedakan nilai mean antara harapan dengan persepsi dan perbedaan tersebut berlangsung dalam kelompok sampel yang sama (pelanggan sama, mengisi kuesioner sama). Untuk mengetahui indikator-indikator Kualitas Pelayanan apa saja yang masuk ke dalam kuadran A, B, C, atau D. Untuk setiap pilihan yang akan dipilih oleh responden di setiap pernyataan akan diberikan poin yang berbeda. Menggunakan 5 skala mulai dari sangat tidak baik (STB), tidak baik (TB), cukup baik (CB), baik (B) dan sangat baik (SB). Pilihan STB diberikan nilai 1, pilihan TB diberikan nilai 2, pilihan CB diberikan nilai 3, pilihan B diberikan nilai 4 dan pilihan SB diberikan nilai 5.

Maka akan mendapatkan mean persepsi (Xi) dan mean harapan (Yi) dari setiap poin pernyataan di dalam kuisioner penelitian. Untuk mendapatkan nilai gap antara persepsi dengan harapan, hasil $\mathrm{Xi}$ dikurangkan dengan hasil Yi. Gap = Xi-Yi. Lalu untuk mendapatkan Tingkat kesesuaian responden (TKi\%) dari sebuah item pernyataan kuisioner aspek transportasi maka hasil Xi dibagi dengan Yi dikali 100\% .

$$
\mathrm{TK}_{\mathrm{i}}=\frac{\mathrm{Xi}}{\mathrm{Yi}} \times 100 \%
$$

(John Martila and John C. James yang dikutip oleh J. Supranto, 2006: 241)

Dengan, $\mathrm{TKi}=$ Tingkat kesesuaian responden, $\mathrm{Xi}=$ Skor penilaian kinerja perusahaan, dan $\mathrm{Yi}$ $=$ Skor penilaian kepentingan pelanggan.

Menurut J. Supranto, 2006: 242, skor untuk setiap tingkat kesesuaian responden (TKi\%) dapat dikategorikan menjadi; $0 \%-32 \%=$ sangat tidak baik, 33\% - $65 \%=$ Tidak baik, $66 \%-99 \%=$ Cukup baik, $100 \%=$ Baik dan $>100 \%=$ Sangat baik. Setelah mencari hasil Xi dan Yi dari masingmasing item pernyataan, lalu hasil tersebut dibagi oleh jumlah responden yang menjawab kuesioner tersebut. Untuk mendapatkan harga $\overline{X i}$ dan $\overline{Y i}$. (J. Supranto, 2006: 241)

$$
\overline{X i}=\Sigma \mathrm{Xi} / \mathrm{n}
$$

Dengan, $\overline{X i}=$ mean persepsi dari seluruh responden untuk satu item Pernyataan dan $\mathrm{N}=$ jumlah responden. (J. Supranto, 2006: 241)

$$
\overline{Y i}=\Sigma \mathrm{Yi} / \mathrm{n}
$$

Dengan, $\overline{Y i}=$ mean harapan dari seluruh responden untuk satu item Pernyataan dan $\mathrm{N}=$ jumlah responden. Sehingga akan didapatkan mean harapan dan mean persepsi dari setiap pernyataan di dalam kuisioner yang nanti akan digunakan untuk mencari nilai c-line pada tahap selanjutnya. Pertama, peneliti harus menentukan c-line untuk sumbu x dan c-line untuk sumbu y. Pertanyaan pada item 1 diisi dengan butir pernyataan 1 sesuai kuesioner penelitian. Lalu, kolom mean persepsi 
diisi dengan nilai mean keseluruhan penilaian responden terhadap Pernyataan 1. Demikian pula dengan mean harapan diisi dengan nilai mean keseluruhan responden dalam menanggapi Pernyataan 1 dan kolom gap diisi dengan mean persepsi dikurangi mean harapan. lalu sertakan juga Tki $\%$ nya ke dalam tabel. $C$-Line mean persepsi akan menjadi $c$-line sumbu x. $C$-Line mean harapan akan menjadi $c$-line sumbu y. Cara mencarinya adalah peneliti membuat Tabel berikut:

Tabel 2. Importance Performance Analysis

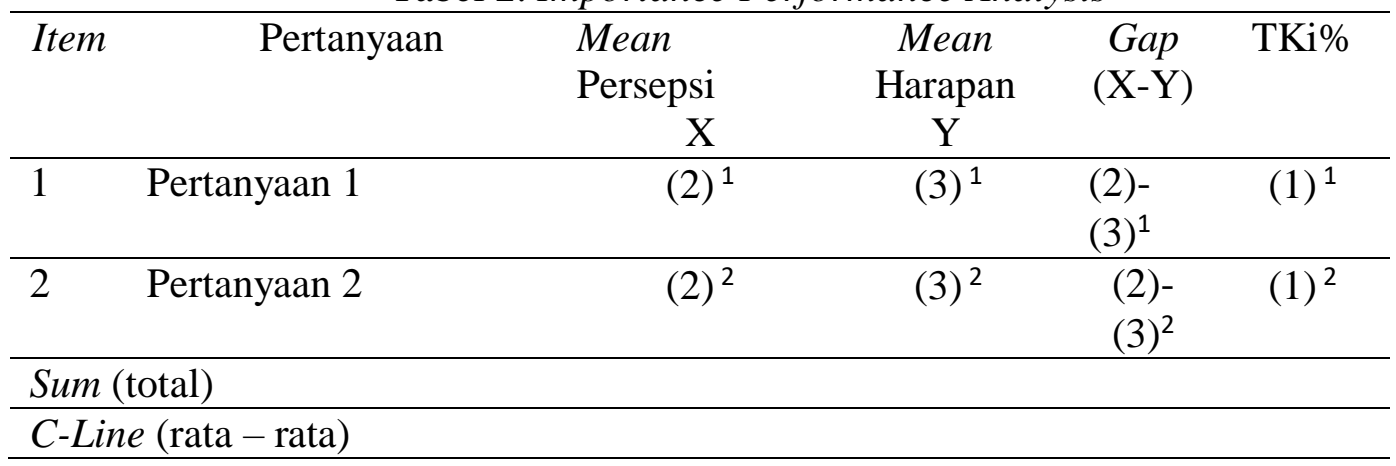

C. Metode Survei Lapangan

Durasi Parkir

$$
\mathrm{DP}=\mathrm{Ex}-\mathrm{En}
$$

Menurut Leksmono S. Putranto. 2013, dengan, DP = Durasi parkir (menit), Ex = Waktu saat kendaraan keluar dari ruang parkir (menit), dan $\mathrm{En}=$ Waktu saat kendaraan masuk ke ruang parkir (menit)

Untuk menghitung rata-rata durasi parkir menggunakan rumus sebagai berikut:

$$
\overline{D P}=\Sigma \mathrm{DP} / \mathrm{n}
$$

Dengan, $\overline{D P}=$ Rata-rata durasi parkir (menit), $\Sigma \mathrm{DP}=$ Jumlah durasi parkir semua kendaraan (menit), dan $\mathrm{n}=$ Jumlah kendaraan yang durasinya terhitung (menit)

Indeks Parkir

Indeks parkir dirumuskan sebagai berikut : Ip $=\frac{\text { Akumulasi Parkir }}{\text { Ruang Parkir Tersedia }}$

(6)

Dimana akumulasi parkir didapat dari:

Akumulasi $=$ Kendaraan di Lokasi + Kendaraan Masuk - Kendaraan Keluar

- IP $<1$ artinya bahwa fasilitas parkir tidak bermasalah, dimana kebutuhan parkir tidak melebihi daya tampung/kapasitas normal.

- $\quad$ IP = 1 artinya bahwa kebutuhan parkir seimbang dengan daya tampung/kapasitas normal.

- $\quad$ IP > 1 artinya bahwa fasilitas parkir bermasalah, dimana kebutuhan parkir melebihi daya tampung/kapasitas normal.

\section{ANALISIS DATA}

Pengumpulan data

Data kapasitas, durasi dan indeks parkir diperoleh dengan metode survey langsung di lapangan. Data survei kuesioner diperoleh dari kuesioner responden yang disebar kepada pengguna tempat peristirahatan di KM 88ATol Purbaleunyi dan data aspek transportasi juga didapat dengan melakukan survei langsung di lapangan. Data kuesioner pengguna didapat dari 100 responden dengan penyebaran kuesioner dengan wawancara langsung di tempat peristirahatan KM 88A Tol 
Purbaleunyi sebanyak 50 orang dan melalui on line sebanyak 50 orang. Dari hasil kuesioner yang diolah dengan metode IPA. Dengan demikian akan diperoleh kepuasan pengunjung terhadap fasilitas tempat peristirahatan KM 88A tol Purbaleunyi (Agustinah , U. 2015; Algifari.2016 dan Lodhita, H.E. 2012)

\section{Hasil survei dengan metode IPA}

Gambar diagram kartesius menunjukkan kepuasan pengunjung terhadap fasilitas di tempat peristirahatan:

- $\quad$ Poin 1, akses dari jalan tol menuju ke tempat peristirahatan: mudah, petunjuk jelas, dan tidak membingungkan. memiliki nilai mean persepsi 3.91, nilai mean harapan 4.96, nilai gap 1.05 dan tingkat kepuasan sebesar $78.83 \%$. Poin ini berada di kuadran B, yang berarti kualitas pelayanan poin 1 sudah memuaskan, sehingga pengelola harus mempertahankan kualitas.

- $\quad$ Poin 2, kondisi permukaan jalan di dalam area tempat peristirahatan: rata, halus dan tidak berlubang. Memiliki nilai mean persepsi 3.58, nilai mean harapan 4.96, nilai gap 1.38 dan tingkat kepuasan sebesar $72.18 \%$. Poin ini berada di kuadran A, yang berarti kualitas pelayanan pada poin 2 masih belum memuaskan. Pengelola harus segera memperbaiki kualitas pelayanan dengan memperbaiki perkerasan jalan di dalam area tempat peristirahatan.

- $\quad$ Poin 3, kondisi permukaan jalan di jalur masuk (ramp in): rata, halus dan tidak berlubang. Memiliki nilai mean persepsi 3.89, nilai mean harapan 4.96, nilai gap 1.07 dan tingkat kepuasan sebesar $78.43 \%$. Poin ini berada di dalam kuadran B, yang berarti kualitas pelayanan pada poin 3 sudah memuaskan, namun harus tetap mempertahankan kualitas.

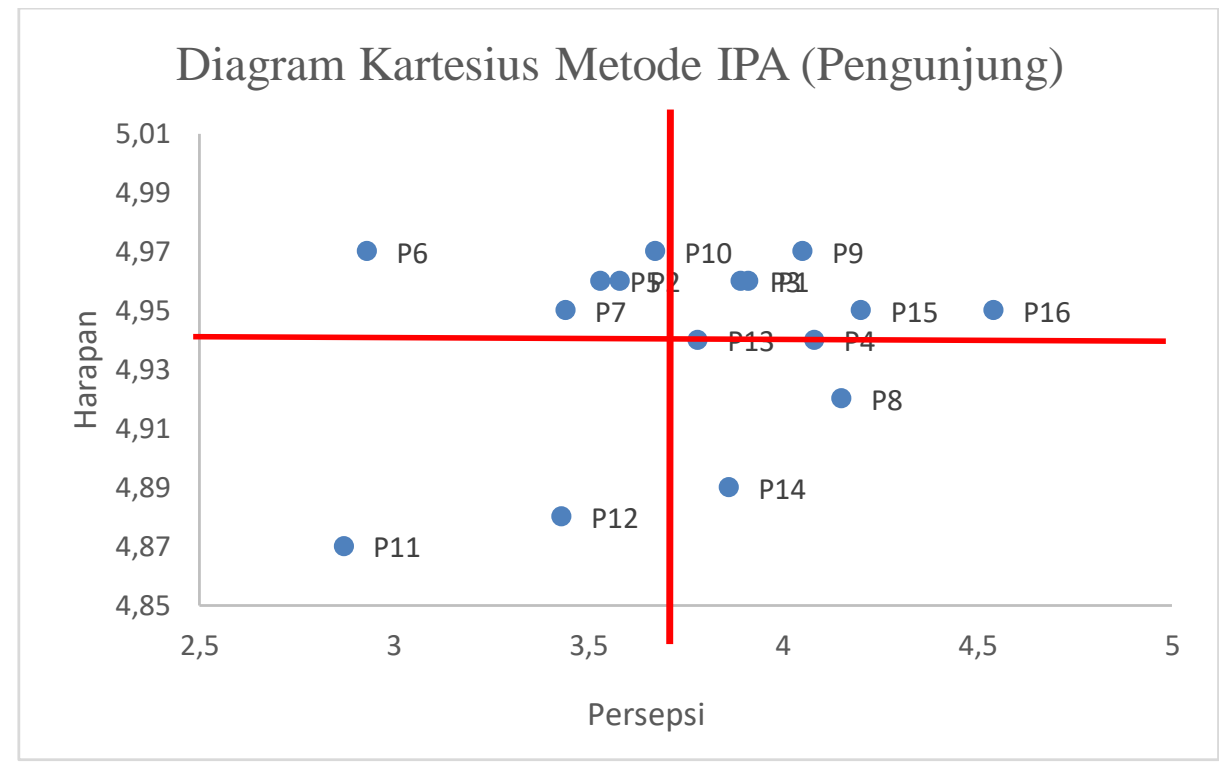

Gambar 2. Diagram Kartesian Metode IPA (Pengunjung)

- $\quad$ Poin 4, kondisi permukaan jalan di jalur keluar (ramp out) tempat peristirahatan: rata, halus dan tidak berlubang. Memiliki nilai mean persepsi 4.08, nilai mean harapan 4.94, nilai gap 0.86 dan tingkat kepuasan sebesar $85.59 \%$. Poin ini berada di dalam kuadran B, yang berarti kualitas pelayanan pada poin 4 sudah memuaskan, namun tetap harus mempertahankan kualitas pelayanan, yang diharapkan menjadi faktor penunjang bagi kepuasan konsumen. 
- $\quad$ Poin 5, kejelasan dan ketepatan petunjuk arah dalam area tempat peristirahatan: mudah dilihat, tepat dan tidak membingungkan. Memiliki nilai mean persepsi 3.53, nilai mean harapan 4.96, nilai gap 1.43 dan tingkat kepuasan sebesar $71.17 \%$. Poin ini berada di kuadran A, yang berarti kualitas pelayanan masih kurang baik. Pengelola harus segera memperbaiki kualitas pelayanan, dengan memperjelas serta menempatkan petunjuk arah yang benar.

- $\quad$ Poin 6, ketersediaan jumlah tempat parkir untuk kendaraan. Memiliki nilai mean persepsi 2.93, nilai mean harapan 4.97, nilai gap 2.04 dan tingkat kepuasan sebesar 58.95\%. Poin ini berada di kuadran A, yang berarti kualitas pelayanan kurang baik dan poin ini memiliki kualitas pelayanan dengan tingkat kepuasan terendah dari poin - poin lain. Pengelola harus segera memperbaiki kualitas pelayanan, dengan memperluas lahan tempat peristirahatan, sehingga dapat menambah jumlah slot parkir agar dapat memenuhi kebutuhan.

- $\quad$ Poin 7, luas satu slot tempat parkir kendaraan di tempat peristirahatan (jarak antar slot parkir). Memiliki nilai mean persepsi 3.44, nilai mean harapan 4.95, nilai gap 1.51 dan tingkat kepuasan sebesar $69.49 \%$. Poin ini berada di kuadran A, kualitas pelayanan masih kurang memuaskan, dibeberapa titik terdapat slot parkir yang terlalu sempit sehingga pengunjung susah untuk parkir. Pihak pengelola harus memperluas slot tempat parkir.

- $\quad$ Poin 8, Akses menuju ke stasiun pengisian bahan bakar (mudah dicapai, petunjuk jelas, jalan tidak berlubang) memiliki nilai mean persepsi 4.15 , nilai mean harapan 4.92, nilai gap 0.77 dan tingkat kepuasan sebesar $84.36 \%$. Poin ini berada di kuadran D, poin ini dinilai sudah memuaskan, namun tidak terlalu penting bagi pengunjung. Diharapkan pengelola mengalokasikan dana untuk poin yang membutuhkan perbaikan maupun peningkatan.

- $\quad$ Poin 9, ketersediaan jumlah toilet umum di tempat peristirahatan. Memiliki nilai mean persepsi 4.05, nilai mean harapan 4.97, nilai gap 0.92 dan tingkat kepuasan sebesar $81.49 \%$. Poin ini berada di kuadran B, yang berarti kualitas pelayanan sudah memuaskan. Pihak pengelola harus mempertahankan kualitas pelayanan.

- $\quad$ Poin 10, fungsi dan kebersihan toilet umum (beroperasi dengan baik/ tidak rusak). Memiliki nilai mean persepsi 3.67, nilai mean harapan 4.97, nilai gap 1.3 dan tingkat kepuasan sebesar 73.84\%. Poin ini berada di kuadran A, yang berarti kualitas pelayanan belum memuaskan. Pengelola harus menjaga kebersihan toilet agar memberikan kenyamanan pada pengunjung.

- $\quad$ Poin 11, ketersediaan fasilitas tempat makan dan minum di tempat peristirahatan (Tidak perlu mengantri/ menunggu lama). Memiliki nilai mean persepsi 2.87, nilai mean harapan 4.87, nilai gap 2 dan tingkat kepuasan sebesar 58.93\%. Poin ini berada di kuadran C, yang berarti belum memuaskan tapi tidak terlalu penting bagi pengunjung.

- Poin 12, fungsi dan kebersihan tempat makan dan minum di tempat peristirahatan (beroperasi dengan baik/ tidak rusak). Memiliki nilai mean persepsi 3.43, nilai mean harapan 4.88, nilai gap 1.45 dan tingkat kepuasan sebesar 70.29\%. Poin ini berada di kuadran C, yang berarti kualitas pelayanan belum memuaskan dan tidak terlalu penting bagi pengunjung.

- $\quad$ Poin 13, ketersediaan tempat beribadah untuk pengunjung (Tempatnya luas dan mencukupi pengunjung). Memiliki nilai mean persepsi 3.78, nilai mean harapan 4.94, nilai gap 1.16 dan tingkat kepuasan sebesar 76.52\%. Poin ini berada di kuadran B, Poin ini dinilai sudah memuaskan, oleh karena itu pengelola harus mempertahankan kualitas pelayanan poin 13 .

- $\quad$ Poin 14, fungsi dan kebersihan tempat beribadah (Beroperasi dengan baik/ tidak rusak). Memiliki nilai mean persepsi 3.86, nilai mean harapan 4.89, nilai gap 1.03 dan tingkat kepuasan sebesar 78.94\%. Poin ini berada di kuadran D, poin ini dinilai sudah memuaskan bagi pengunjung, namun tidak terlalu penting. Pengelola bisa mengalokasikan dana untuk meningkatkan kualitas pelayanauntuk poin yang masih kurang memuaskan.

- $\quad$ Poin 15, jumlah stasiun pengisian bahan bakar. Memiliki nilai mean persepsi 4.2, nilai mean harapan 4.95 , nilai gap 0.75 dan tingkat kepuasan sebesar $84.85 \%$. Poin ini berada di kuadran 
B, yang berarti dinilai sudah memuaskan. Pengelola diharapkan dapat mempertahankan kualitas pelayanan agar dapat menjadi faktor penunjang kepuasan pengunjung.

- $\quad$ Poin 16, kelengkapan Stasiun Bahan Bakar. Memiliki nilai mean persepsi 4.54, nilai mean harapan 4.95, nilai gap 0.41 dan tingkat kepuasan sebesar $91.72 \%$. Poin ini berada di kuadran B, dinilai sudah memuaskan. Pengelola harus mempertahankan kualitas pelayanan poin 16 .

Hasil survei dengan metode observasi

Data survei tempat peristirahatan terdiri dari kapasitas ruang parkir, data keluar masuk kendaraan, durasi parkir, indeks parkir dan denah site layout tempat peristirahatan. Data ini dihitung menggunakan rumus sesuai dengan formula yang ada. Dari setiap data akan diolah untuk mendapatkan karakteristik tempat peristirahatan KM 88A Tol Purbaleunyi berdasarkan aspek transportasi.

Data hasil observasi:

A. Kapasitas Parkir.

Berdasarkan hasil observasi diperoleh kapasitas parkir pada tempat peristirahatan $\mathrm{km} \mathrm{88 \textrm {A }}$ sebanyak 117 slot pakir

B. Durasi Parkir.

Durasi parkir rata - rata diperoleh sebesar 28 menit 39 detik

C. Indeks Parkir

Rata- rata indeks parkir pada tempat peristirahatan $\mathrm{km} 88 \mathrm{~A}$ berada diatas angka 1, yang berarti kebutuhan parkir melebihi kapasitas parkir kendaraan.

\section{KESIMPULAN}

1. Dari hasil kuesioner yang telah dibagikan kepada responden mengenai fasilitas dan pelayanan berdasarkan SPM di tempat peristirahatan $\mathrm{km} 88 \mathrm{~A}$, ada beberapa fasilitas yang masih kurang baik, salah satunya ada tempat parkir. Ketersediaan tempat parkir di tempat peristirahatan km 88A dapat dibilang tidak mencukupi kapasitas parkir, dilihat dari hasil tingkat kepuasan responden hanya sebesar $58.96 \%$. Selain itu ketersediaan tempat makan memiliki nilai tingkat kepuasan terendah dengan nilai 58.93\%. Kondisi perkerasan di dalam tempat peristirahatan juga kurang baik dengan tingkat kepuasan sebesar $72.17742 \%$. Beberapa fasilitas lainnya yang dinilai masih kurang oleh pengunjung adalah luas slot parkir, kebersihan toilet, kebersihan tempat makan dan ketepatan petunjuk arah. Namun ada beberapa fasilitas yang dinilai memuaskan oleh pengunjung, seperti ketersediaan jumlah toilet, Jumlah stasiun pengisian bahan bakar, dan kelengkapan bahan bakar. Fasilitas dan pelayan lainnya seperti kondisi jalan masuk dan keluar tempat peristirahatan, ketersediaan dan kebersihan tempat beribadah sudah cukup baik.

2. Persepsi kepuasan rata -rata pengunjung terhadap tempat peristirahatan $88 \mathrm{~A}$ adalah sebesar 3.7444, yang berarti kinerja dari tempat peristirahatan belum memuaskan bagi pengunjung.

3. Kapasitas parkir pada tempat peristirahatan km 88A hanya berjumlah 117 slot parkir. Hasil survei menunjukkan kebutuhan parkir lebih besar dari kapasitas parkir yang ada. Pengelola harus segera menambah kapasitas parkir, karena akan menghambat sirkulasi lalu lintas di dalam tempat peristirahatan terutama pada saat weekend.

\section{REFERENSI}


Agustinah, U. (2015). "Perencanaan dan Perancangan Rest Area Wilayah Suramadu di Kabupaten Bangkalan Madura", Seminar Nasional Sains dan Teknologi. Vol 3. Hlm 618.

Atmi, Fety Widi. (2014(. Rest Area Jalan Sragen - Ngawi Km 14 Sragen

Abubakar. (2012). "Suatu Pendekatan Untuk Mengelola Dan Mengendalikan Lalulintas". Transindo Gautama Media.

Adelia Destiasri. (2011) . Rest Area KM 22 Jalan Tol Semarang - Solo. Fakulas Teknik. Universitas Diponegoro.

Atri, Yuanita Setyo. (2010). Rest Area Sebagai Fasilitas Transit Bagi Pengguna Jalan Raya Saradan Kawasan Hutan Jati Sektor II Madiun. Fakultas Teknik.Universitas Sebelas Maret: Surakarta

Algifari. (2016). Mengukur kualitas layanan dengan indeks kepuasan, metode importance performance analysis.

Brandt, Latu, dan Everett. (2000). "Importance Performance Analysis method"

Departemen Perhubungan Direktur Jenderal Perhubungan Darat. 1996. "Pedoman Teknis Penyelenggaraan Fasilitas Parkir". Departemen Perhubungan. Jakarta.

Departemen Pekerjaan Umum. (20099. "Geometri Jalan Bebas Hambatan untuk Jalan Tol". Direktur Jenderal Bina Marga.

Direktorat Jenderal Bina Marga. (2004). "Panduan Survai dan Perhitungan Waktu Perjalanan Lalulintas". www.pu.go.id/Ditjen_Prasarana\%20Wil/referensi/nspm

J.A. Martilla, J.C. James. (1977). "Importance Performance Analysis". Journal of Marketing, January.

Kementrian Pekerjaan Umum dan Perumahan Rakyat. (2018). Peraturan Menteri Pekerjaan Umum dan Perumahan Rakyat Nomor10/PRT/M/2018 tentang Tempat Istirahat dan Pelayanan pada Jalan Tol, Jakarta.

Leksmono S. Putranto, Ph. D. (2013). "Rekayasa Lalu-Lintas,” Edisi 2, PT Indeks, Jakarta.

Lodhita, H.E, et al. (2012). “Analisis Tingkat Kepuasan Mahasiswa Program Studi Pendidikan Bahasa Inggris terhadap Pelayanan Program Studi Pendidikan Bahasa Inggris STKIP Siliwangi Bandung", Volume 9.

Peraturan Menteri Pekerjaan Umum Republik Indonesia Nomor 16 Tahun 2014 Tentang Standar Pelayanan Minimal Jalan Tol.

Peraturan Pemerintah Republik Indonesia. (2005). "Nomor 15 Tentang Jalan Tol”. Jakarta: Lembaran Negara Republik Indonesia Tahun 2005 Nomor 32.

Radiansyah, S. (2017). “Dampak Pembangunan Ruas Tol Purbaleunyi”. Jurnal penelitian \& PPM, Vol 4, Hlm 355.

Situmorang. M. L. (2014). Rest Area sebagai Penunjang Mobilitas yang Rekreatif di Sumatera Utara. Skripsi. Tidak diterbitkan. Fakultas Teknik.Universitas Gajah Mada: Yogyakarta.

Munawar, A. (2004). "Manajemen Lalulintas Perkotaan". Beta Offset. Yogyakarta.

Murwono, J. (1996). "Pengantar Teknik dan Perencanaan Transportasi".UGM Yogyakarta.

Situmorang, Margaretha Liliana. (2014). Rest Area sebagai PenunjangMobilitas yang Rekreatif di Sumatera Utara. Fakultas Teknik.Universitas Gajah Mada: Yogyakarta.

Yuanita, S.A. (2010). Rest Area Sebagai Fasilitas Transit Bagi Pengguna Jalan Raya Saradan Kawasan Hutan Jati Sektor II Madiun. Fakultas Teknik. Universitas Sebelas Maret: Surakarta. 